\title{
Central giant cell granuloma of the mandibular condyle. Case-report
}

\author{
Munzenmayer $\mathrm{J}^{1}$, Tapia $\mathrm{P}^{2}$, Zeballos $\mathrm{J}^{2}$, Martínez $\mathrm{A}^{3}$, Compan $\mathrm{A}^{4}$, Urra $\mathrm{A}^{5}$, Spencer $\mathrm{ML}^{6}$
}

\begin{abstract}
SUMMARY
This case report describes a 19-year-old female patient with a central giant cell granuloma in the left mandibular condyle, treated with en bloc resection and reconstruction with fibula graft. This occurrence is considered very unusual.
\end{abstract}

Rev. Clin. Periodoncia Implantol. Rehabil. Oral Vol. 6(2); 83-86, 2013.

Key words: Central giant cell granuloma, fibula graft, mandibular condyle.

\section{INTRODUCTION}

Central giant cell granuloma (CGCG) is widely considered to be a non-neoplastic lesion. CGCG is a localized osteolitic lesion with varied biologic behavior of aggression which affects the jaw bones ${ }^{(1-6)}$. The etiology of CGCG is unknown, but some indications implicate genetic abnormalities ${ }^{(7-9)}$. The mandible is twice as likely to be involved as the maxillary ${ }^{(1,2,5,6,10)}$. Approximately $10 \%$ of all benign lesions in the mandible are due to CGCG, but only a few cases have involved the mandibular condyle $^{(11-13)}$. Over $60 \%$ of the cases described in the literature occur in patients under 30 years of age, although CGCG may also develop in children and the elderly ${ }^{(1,2,5,6,14,15)}$. Females are more frequently affected than males $^{(1,2,5,6,10,16)}$.

Based on clinical and radiographic features, several groups of clinicians have proposed that CGCG of the jaw may be divided into nonaggressive and aggressive lesions ${ }^{(3-5)}$. Most cases are non-aggressive, exhibit few or no symptoms, and are detected coincidentally at the time of the radiologic dental exam ${ }^{(5)}$.

The aggressive pattern is characterized by large lesions with swelling of the jaw, rapid growth, pain, paresthesia, cortical bone perforation or thinning, root resorption, and recurrence ${ }^{(3-5,10,14)}$.

Radiologic findings of the non-aggressive type, which appears as a well-circumscribed radiolucent lesion, are generally not associated with the teeth and do not expand the cortical. The aggressive variant usually consists of a large lytic lesion, more often multilocular than unilocular, with cortical expansion, displacement of teeth, and rizalisis ${ }^{(1,2,5,10)}$.

Histologically, this lesion is characterized by the presence of numerous multinucleated giant cells in a fibro-vascular stroma, hemorrhagic foci with hemosiderin pigments, and occasionally areas of osteoid tissue ${ }^{(1,3,5,10)}$.

CGCG can be treated with several therapies, including surgical excision, simple curettage ${ }^{(3,5,6,10,16,17,18)}$, and en bloc resection ${ }^{(5,6,13,14)}$ as well as intralesional corticosteroid injections ${ }^{(15)}$, calcitonin intradermal injection or nasal spray ${ }^{(10,19)}$, and alpha-interferon -2a (IFN- $\alpha$ 2-a) injections $^{(20,21)}$. All these treatments have had varying success.

In the literature, recurrence rates range from 11.0 to $49.0 \%$ or greater, depending on the behavior and/or treatment ${ }^{(1-5,10,14,20,21)}$.

We report a case of central giant granuloma developing in the left mandibular condyle treated with en bloc resection and reconstruction with fibula graft. To our knowledge, this is a rare condition with few reports in the english literature.

\section{CASE-REPORT}

A 19-year-old chilean female was referred to the Service of Head and Neck Surgery at Guillermo Grant Benavente Hospital of Concepción, because her general practitioner discovered a radiolucent area on the left mandibular condyle during a routine panoramic radiograph. Clinical examination revealed no facial asymmetry, and the overlying skin in the left preauricular region appeared to be normal. The patient did not experience pain, restrictions of mandibular movements, or occlusal disturbances. An intraoral examination showed no bony expansion and a normal mucosa. There was no contributory medical history, and no lymph node involvement was detected. The results of all hematological studies were within normal limits. Laboratory values for serum calcium, phosphorus, alkaline phosphatase, and parathyroid hormone (PTH) were within normal limits, ruling out the brown tumor of hyperparathyroidism. The panoramic radiograph (Figure 1) revealed a well-circumscribed, multilocular, corticated radiolucency of the left mandibular condyle. No tooth displacement or resorption of the root apices was present. The CT scan revealed an expansible lesion perforating the cortical bone (Figure 2).

Surgery was performed under general anesthesia. Two teams of surgeons worked simultaneously on the right leg and the lesion of the left mandibular condyle. Preauricular and submandibular incisions were made. By accessing the temporomandibular joint (TMJ), the lesion was removed en bloc with a bony security margin of $1 \mathrm{~cm}$ using a reciprocating saw and protecting the internal maxillary artery (Figure 3 ). The articular disc was preserved.

A fibula graft of appropriate length and without a vascular pedicle was molded and adapted after using an intermaxillary wire fixation to maintain the vertical dimension. Once adapted, the graft was fixed by 2.0 rigid osteosynthesis with four bi-cortical screws, two for each side of the gap between the mandibular ramus and the fibula graft (Figure 4). The intact disc was repositioned using absorbable sutures (Vicryl 3.0). The intermaxillary fixation was removed and the occlusion was tested. Tissues were closed in layers: the deep layers with 4.0 Vicryl and the skin with monofilament Nylon 5.0. Face muscle functions were verified when the patient regained consciousness. No facial nerve injury was detected. The occlusion was maintained related to the preoperative state, without limitations of movement or pain. The postoperative course was uneventful.

Gross examination of the surgical specimen showed a mandibular condyle bone segment that measured $4 \times 2.2 \times 1.2 \mathrm{~cm}$. Sections through the lesion showed reddish and yellow areas. The

1. DDS. Maxillofacial Surgeon. Assistant Professor, Department of Oral Surgery. School of Dentistry, Universidad de Concepción. Head and Neck Surgery Team of the Hospital Regional Guillermo Grant Benavente. Concepción, Chile.

2. DDS. Graduate Student of Oral and Maxillofacial Surgery. School of Dentistry, Universidad de Concepción, Chile.

3. DDS. Professor. Department of Oral Pathology. School of Dentistry, Universidad de Concepción, Chile.

4. MS. Head and Neck Surgeon, Head and Neck Surgery Team of the Hospital Regional Guillermo Grant Benavente. Concepción, Chile.

5. MS. Otolaryngologist. Head and Neck Surgery Team of the Hospital Regional Guillermo Grant Benavente. Concepción, Chile.

6. MS. Assistant Professor. Department of Oral Pathology. School of Dentistry, Universidad de Concepción, Chile.

Correspondence author: Alejandra Martínez. almartin@udec.cl / almartinbe@gmail.com. Trabajo recibido el 30/11/2012. Aprobado para su publicación el 18/03/2013. 
microscopic examination revealed multinucleated giant cells dispersed throughout a hypercellular, fibrovascular stroma and extravascular hemosiderin pigment (Figure 5). The section margins were free of the lesion. Given the aforementioned histopathological and serological findings, the present case was diagnosed as a CGCG.

Informed consent was obtained from the patient and this report was approved by the Ethics Committee of the Guillermo Grant Benavente Hospital.

No evidence of clinical or radiological recurrence was observed during 24 months of follow-up (Figure 6).

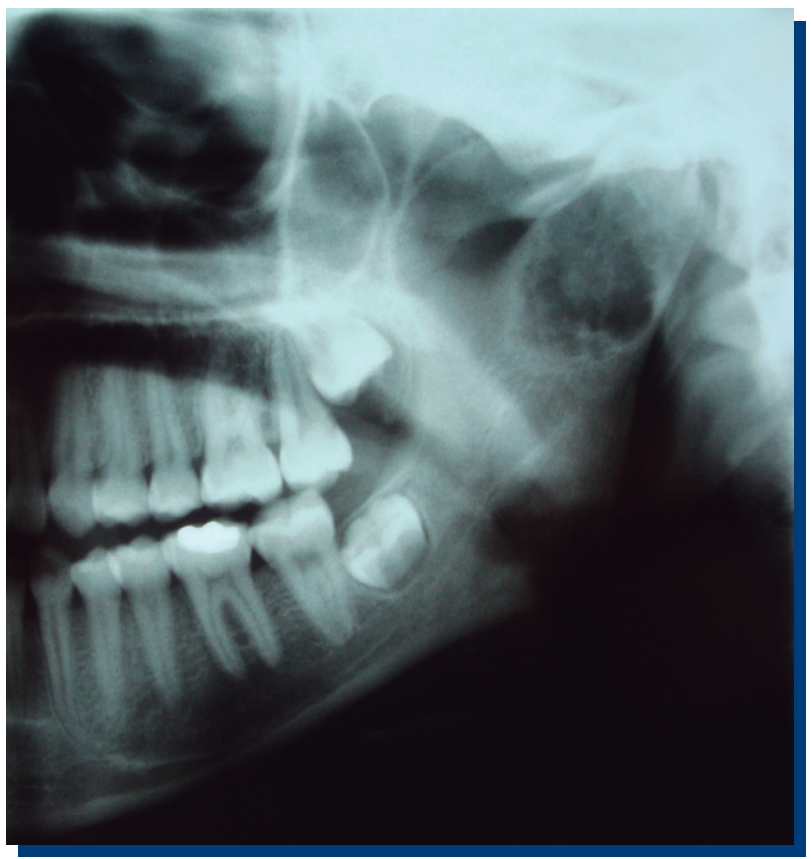

Figure 1. Panoramic radiograph demonstrated a well-circumscribed, multilocular, radiolucent lesion of the left condyle.

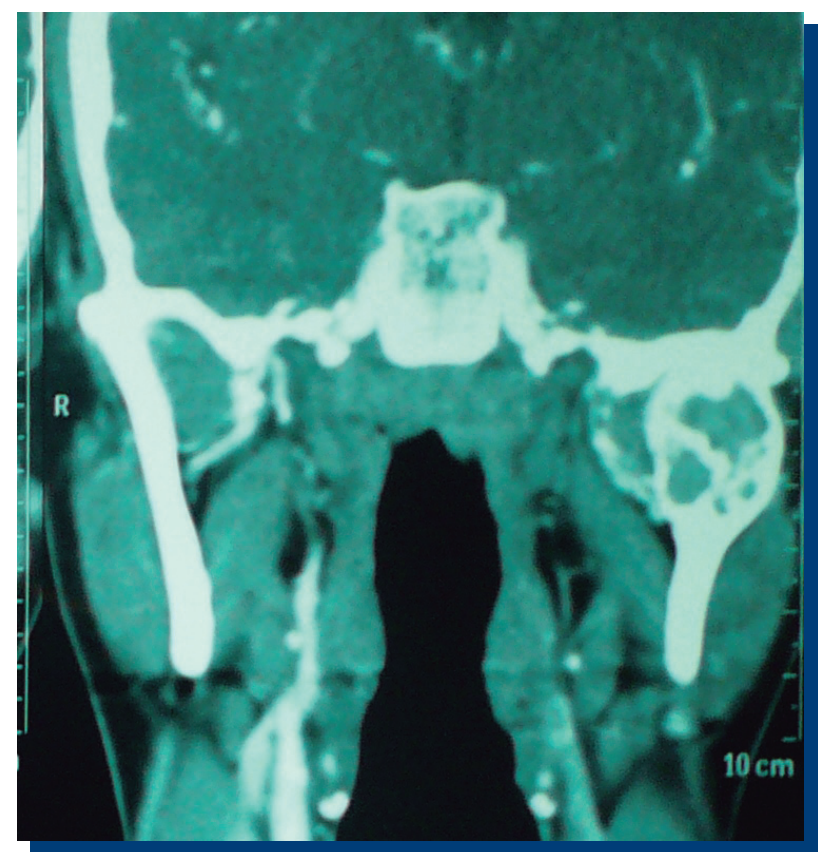

Figure 2. Coronal CT shows an expansible, destructive, radiolucent lesion of the left condyle.

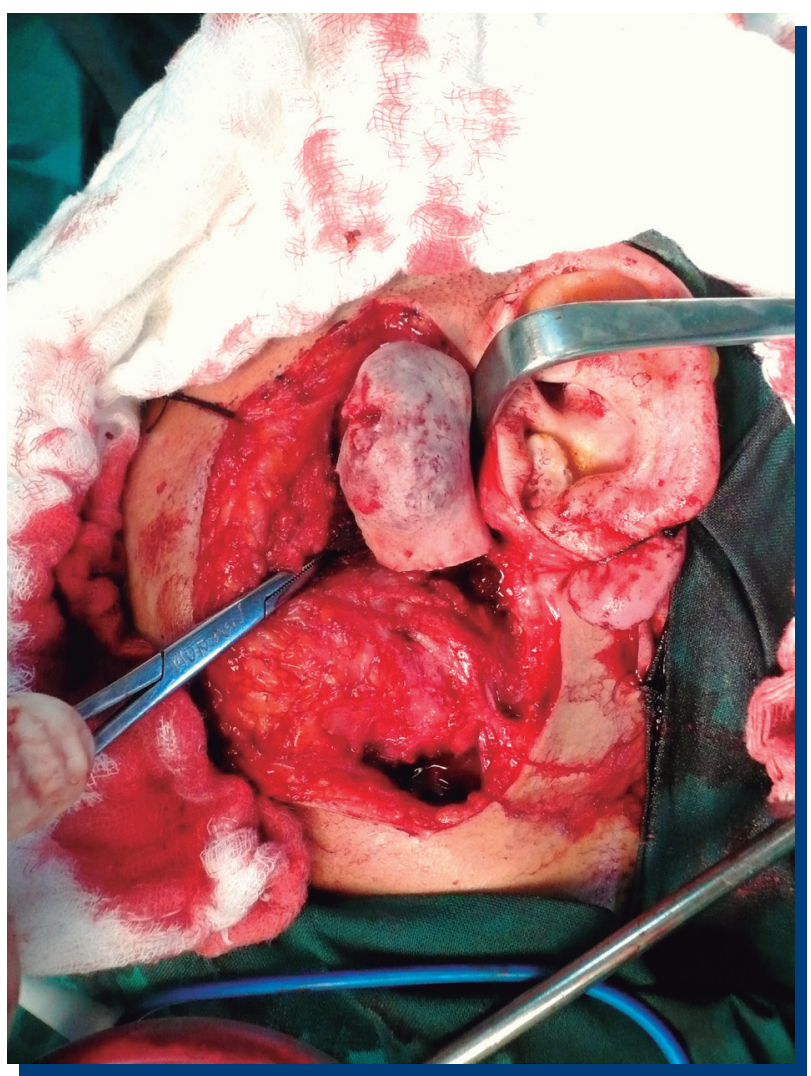

Figure 3. Intraoperative view of the resection of the lesion.

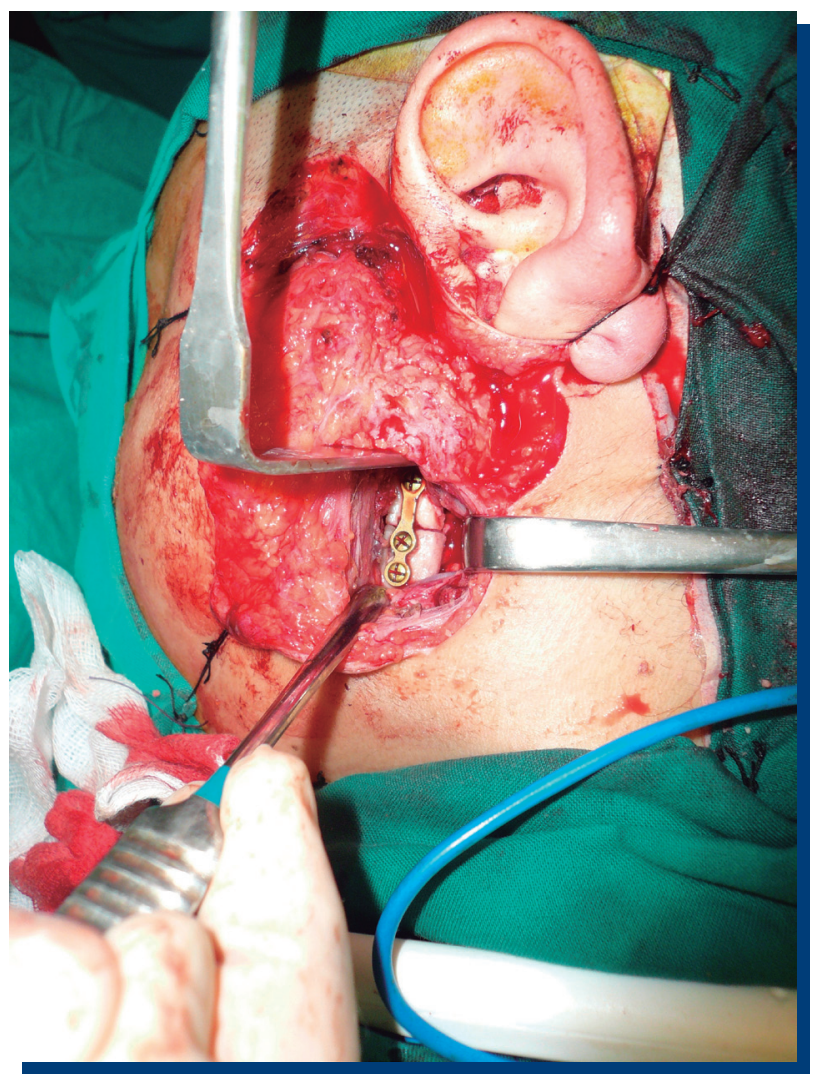

Figure 4. Intraoperative view of the fibula graft fixed with 2.0 rigid osteosynthesis. 


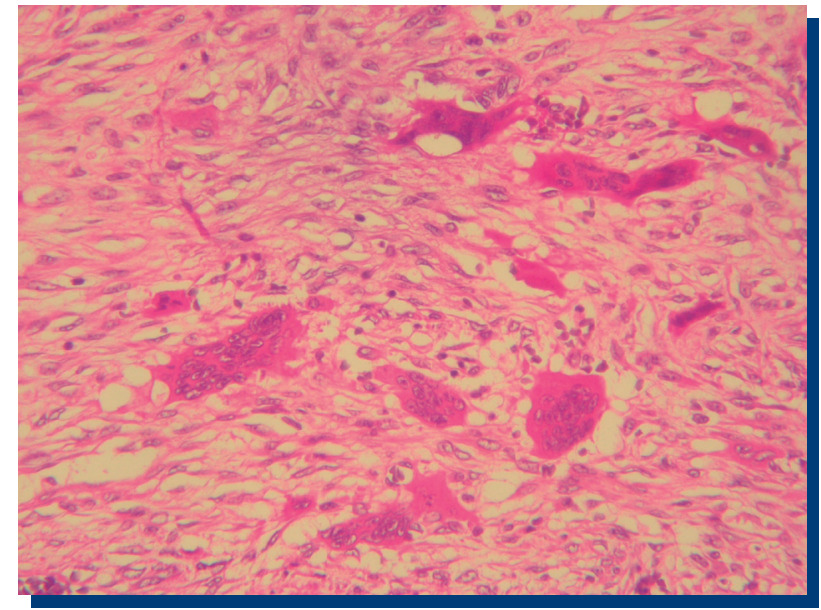

$\overline{\text { Figure 5. Representative photomicrograph shows large giant cells that are distributed }}$ in fibrovascular stroma $(H / E, x 40)$.

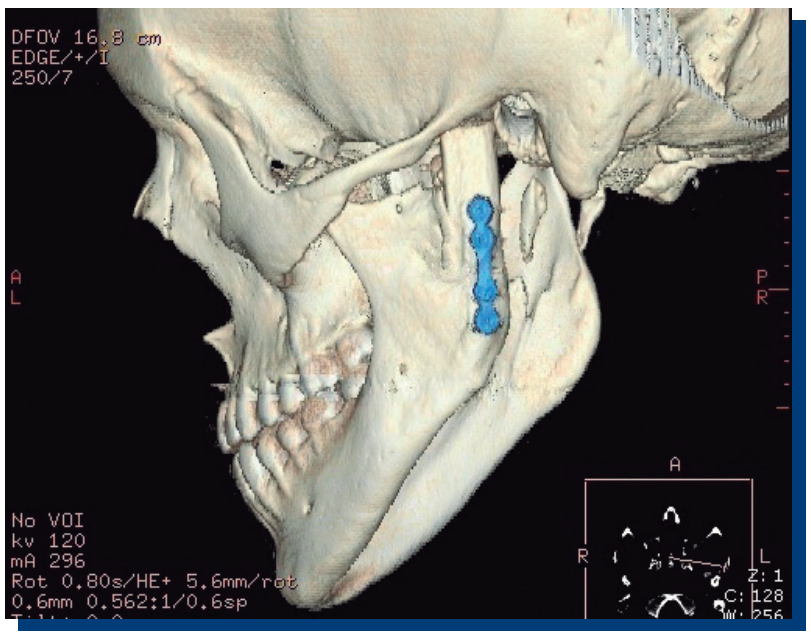

Figure 6. Three-dimensional computer tomography.

\section{DISCUSSION}

The clinical and pathological findings presented in this case corroborate CGCG, per the characteristics reported in the literature. The lesion was typical in that it was found in the mandible of a female patient in the second decade of life ${ }^{(1-6)}$, but its location in the mandibular condyle was unusual. The mandibular condyle is a very uncommon site for CGCG, and few cases are reported in the literature ${ }^{(11-13)}$. The occurrence of such lesions in the mandibular condyle generates a diagnostic and therapeutic challenge for oral and maxillofacial surgeons.
Therapeutic options for CGCG have varied greatly over the years. Medical therapeutic approaches such as alpha interferon (alphaIFN) ${ }^{(20,21)}$, calcitonin ${ }^{(10,19)}$, and intralesional injections of corticosteroids ${ }^{(15)}$ have been described. The benefits of these treatments may make them worthwhile, especially in cases of large lesions that would result in significant deformity if treated surgically $(15,19,20)$.

Surgery is considered to be the traditional treatment, and it is still the most accepted one. Nonetheless, the literature shows that not all clinicians agree on the type of surgery that should be performed. Surgical management of CGCG may be achieved with simple curettage or en bloc resection, depending on diverse factors such as location, size, radiographic features, recurrence, and aggressive behavior ${ }^{(5,6,10,14,16-18,20,22)}$.

The treatment of choice is typically surgical curettage of the involved area. In some cases, curettage has been supplemented with cryosurgery $^{(18)}$ or even peripheral ostectomy ${ }^{(6)}$. Recently, Kaban et al. ${ }^{(20)}$ used the technique of curettage followed by adjuvant subcutaneous interferon alpha therapy. This approach appears to be successful in the treatment of aggressive CGCG. According to de Lange et al. ${ }^{(10)}$ surgical curettage is not an effective therapy for CGCG in young people who show aggressive signs and symptoms.

The recurrence rate is variable and depends on the biological behavior of the CGCG. Non-aggressive forms have extremely low recurrence rates and can be treated successfully by enucleation or curettage alone ${ }^{(5,17)}$. Aggressive forms have recurrence rates of $30-70 \%$ with curettage ${ }^{(20)}$. Several studies found a higher propensity for recurrence in younger people ${ }^{(1,10)}$.

Chuong et al.(3) recommended that aggressive lesions that present with pain, rapid growth, facial swellings, or cortical perforation be treated with en bloc resection. This treatment results in the lowest recurrence rate ${ }^{(14)}$. A few single case reports describe the use of this technique followed by reconstruction with autogenously bone grafts(22).

Autogenous reconstruction is desirable when the condyle cannot be salvaged ${ }^{(22)}$. The treatment chosen for the present case was autogenous reconstruction with fibula graft. Little has been published regarding the application of the fibula for reconstructing the mandibular condyle. The fibula seems particularly well suited for condyle replacement, as the bone is tubular in shape, densely cortical, and easily adapted ${ }^{(22)}$.

Resection of CGCG results in a major defect to the patient. This is of great concern, especially in young patients. Early function is a very important feature in any treatment involving the TMJ. In this particular case of CGCG, reconstruction was necessary after the resection of the lesion to reestablish the height of the mandibular ramus and recreate a functional TMJ. A fibula graft was used, providing satisfactory functional and cosmetic results. At 24 months of follow-up, the patient had clinically completely recovered, showing normal joint function and no recurrence of the lesion.

\section{CONFLICT OF INTEREST STATEMENT}

None declared.

\section{REFERENCES}

1. Whitaker SB, Waldron CA. Central giant cell lesions of the jaws. A clinical, radiologic, and histopathologic study. Oral Surg Oral Med Oral Pathol, 1993; 75: 199-208.

2. Kaffe I, Ardekian L, Taicher S, Littner MM, Buchner A. Radiologic features of central giant cell granuloma of the jaws. Oral Surg Oral Med Oral Pathol Oral Radiol Endod, 1996; 81: 720-726.

3. Chuong R, Kaban LB, Kozakewich H, Pérez-Atayde A. Central giant cell lesions of the jaws: A clinicopathologic study. Oral Maxillofac Surg, 1986; 44: 708-713.

4. Whitaker SB, Vigneswaran N, Budnick SD, Waldron CA. Giant cell lesions of the jaws: Evaluation of nucleolar organizer regions in lesions of varying behavior. Oral Pathol Med, 1993; 22: 402-405.

5. Kruse-Lösler B, Diallo R, Gaertner C, Mischke KL, Joos U, Kleinheinz J. Central giant cell granuloma of the jaws: A clinical, radiologic, and histopathologic study of 26 cases. Oral Surg Oral Med Oral Pathol Oral Radiol Endod, 2006; 101: 346-354. 6. Eisenbud L, Stern M, Rothberg M, Sachs SA. Central giant cell granuloma of the jaws: Experiences in the management of thirty-seven cases. J Oral Maxillofac Surg, 1988; 46: 376-384.
7. Wolvius EB, de Lange J, Smeets EE, van der Wal KG, van den Akker HP. Noonan-like/multiple giant cell lesion syndrome: Report of a case and review of the literature. J Oral Maxillofac Surg, 2006; 64: 1289-1292.

8. Edwards PC, Fox J, Fantasia JE, Goldberg J, Kelsch RD. Bilateral central giant cell granulomas of the mandible in an 8-year-old girl with Noonan syndrome (Noonan-like/multiple giant cell lesion syndrome). Oral Surg Oral Med Oral Pathol Oral Radiol Endod, 2005; 99: 334-340.

9. Yazdizadeh M, Tapia JL, Baharvand M, Radfar L. A case of neurofibromatosisNoonan syndrome with a central giant cell granuloma. Oral Surg Oral Med Oral Pathol Oral Radiol Endod, 2004; 98: 316-320.

10. de Lange J, van der Akker HP. Clinical and radiological features of central giantcell lesions of the jaw. Oral Surg Oral Med Oral Pathol Oral Radiol Endod, 2005; 99: 464-470

11. Tasanen A, von Konow L, Nordling S. Central giant cell lesion in the mandibular condyle: Report of a case. Oral Surg Oral Med Oral Pathol, 1978; 45: 532.

12. Shensa DR, Nasseri S. Central giant cell reparative granuloma of the mandibular condyle. J Oral Surg, 1978; 36: 642-643. 
13. Abu-El-Naaj I, Ardekian L, Liberman R, Peled M. Central giant cell granuloma of the mandibular condyle: A rare presentation. J Oral Maxillofac Surg, 2002; 60: 939-941

14. Bataineh AB, Al-Khateeb T, Rawashdeh MA. The surgical treatment of central giant cell granuloma of mandible. J Oral Maxillofac Surg, 2002; 60: 756-761.

15. Carlos R, Sedano HO. Intralesional corticosteroids as an alternative treatment for central giant cell granuloma. Oral Surg Oral Med Oral Pathol Oral Radiol Endod, 2002; 93: $161-166$

16. de Lange J, van den Akker HP, van den Berg H. Central giant cell granuloma of the jaw-a review of the literature with emphasis on therapy options. Oral Med Oral Pathol Oral Radiol Endod, 2007; 104: 603-615.

17. Rawashdeh MA, Bataineh AB, Al-Khateeb T. Long-term clinical and radiological outcomes of surgical management of central giant cell granuloma of the maxilla. $J$ Oral Maxillofac Surg, 2006; 35: 60-66.

18. Webb DJ, Brockbank J. Combined curettage and cryosurgical treatment for the aggressive "giant cell lesion" of the mandible. Int J Oral Maxillofac Surg, 1988; 46: 376-384.
19. de Lange J, van den Akker HP, Veldhuijzen van Zanten GO, Engelshove HA, van den Berg $\mathrm{H}$, Klip $\mathrm{H}$. Calcitonin therapy in central giant cell granuloma of the jaw: A randomized double-blind placebo-controlled study. Int J Oral Maxillofac Surg, 2006; 35: 791-795.

20. Kaban LB, Troulis MJ, Ebb D, August M, Hornicek FJ, Dodson TB. Antiangiogenic therapy with interferon alpha for giant cell lesions of the jaws. J Oral Maxillofac Surg, 2002; 60: 1103-1111.

21. de Lange J, van Rijn RR, van den Berg H, van den Akker HP. Regression of central giant cell granuloma by a combination of imatinib and interferon: A case report. Br J Oral Maxillofac Surg, 2009; 47: 59-61.

22. Engroff SI. Fibula flap reconstruction of the condyle in disarticulation resections of the mandible: A case report and review of the technique. Oral Surg Oral Med Oral Pathol Oral Radiol Endod, 2006; 100: 661-665. 